\title{
Short communication: Concentrations of nonesterified fatty acids and $\beta$-hydroxybutyrate in dairy cows are not well correlated during the transition period
}

\author{
M. M. McCarthy, ${ }^{*}$ S. Mann, $†$ D. V. Nydam, $\dagger$ T. R. Overton, ${ }^{*}$ and J. A. A. McArt ${ }^{1}$ \\ *Department of Animal Science, and \\ †Department of Population Medicine and Diagnostic Sciences, College of Veterinary Medicine, Cornell University, Ithaca, NY 14853
}

\begin{abstract}
The objective was to use longitudinal data of blood nonesterified fatty acids (NEFA) and $\beta$-hydroxybutyrate (BHBA) concentrations to describe the relationship between NEFA and BHBA in dairy cows during the periparturient period. Blood NEFA and BHBA concentration data collected from d 21 prepartum to 21 postpartum for 269 multiparous Holstein cows were selected from 4 different studies carried out within our research groups. Overall, NEFA concentrations were increased beginning near parturition with a relatively steady elevation of NEFA through d 9, after which concentrations gradually decreased. Prepartum BHBA concentrations began to increase beginning several days before parturition, continued to increase during the first week after parturition, and remained elevated through d 21 postpartum. Of the 269 cows included in the data set, 117 cows (43.5\%) had at least one postpartum hyperketonemic event (BHBA $\geq 1.2 \mathrm{mmol} / \mathrm{L})$, and 202 cows (75.1\%) had at least one event of elevated postpartum NEFA concentrations $(\geq 0.70 \mathrm{mmol} / \mathrm{L})$ between 3 and $21 \mathrm{~d}$ in milk. Area under the curve (AUC) was used to investigate relationships between metabolites over time. Overall, the correlations between transition period NEFA and BHBA AUC were weak. We detected a negative correlation between prepartum BHBA AUC and postpartum NEFA AUC $(\mathrm{r}=-0.26)$. A positive correlation existed between postpartum NEFA AUC and postpartum BHBA AUC; however, the correlation coefficient was low $(\mathrm{r}=0.26)$. Large variation was found between the day of maximum NEFA concentration within the first $21 \mathrm{~d}$ in milk and day of maximum BHBA concentration for the same period. The mean and median times of maximum NEFA concentration were 6.8 and $6 \mathrm{~d}$, respectively, whereas the mean and median times of maximum BHBA were 9.6 and $8 \mathrm{~d}$,
\end{abstract}

Received February 9, 2015.

Accepted May 30, 2015.

${ }^{1}$ Corresponding author: jmcart@cornell.edu respectively; however, the range in days for both the mean and median day of maximum concentrations was very large. Overall, our data set indicates a weak relationship between blood concentrations of NEFA and BHBA during the periparturient period of dairy cows, suggesting that elevated concentrations of one should not be extrapolated to suggest elevated concentrations of the other metabolite.

Key words: transition period, nonesterified fatty acids, $\beta$-hydroxybutyric acid, correlation

\section{Short Communication}

Nonesterified fatty acids and BHBA are both used as markers of negative energy balance during the transition period (Ospina et al., 2010a,b; Chapinal et al., 2011; McArt et al., 2012b). Elevation of NEFA or BHBA concentrations during the pre- and postpartum periods have been associated with negative downstream outcomes in individual animals, such as decreased milk production (Duffield et al., 2009; Ospina et al., 2010b; McArt et al., 2012b), decreased reproductive function (Ospina et al., 2010b; McArt et al., 2012b; Garverick et al., 2013), increased risk of health disorders (LeBlanc et al., 2005; McArt et al., 2012a), and increased risk of removal from the herd (Ospina et al., 2010a; Roberts et al., 2012; McArt et al., 2012b), as well as on a herdlevel basis (Ospina et al., 2010c).

In recent literature, these 2 markers of negative energy balance have commonly been presented together (Chapinal et al., 2011; McArt et al., 2013; Ospina et al., 2013). With increased on-farm monitoring of transition period energy metabolism, one of the recurring questions we are asked is how to best interpret the relationship between markers of negative energy balance. Although both NEFA and BHBA are related to negative energy balance, and elevated concentrations of both have independently been shown to increase risk for negative health and production outcomes, there is evidence that they cannot be used interchangeably. Using data from a cross-sectional study in cows sampled 
between 3 and 14 DIM, Ospina et al. (2013) showed that simultaneously sampled blood NEFA and BHBA concentrations had an $\mathrm{r}^{2}$ value of 0.18 , suggesting that only $18 \%$ of the variability in BHBA was explained by NEFA, indicating that these markers are not very well associated when sampled at the same time point. However, to the best of our knowledge, the relationship of NEFA and BHBA over time across the transition period has not been further elucidated. Because crosssectional studies are unable to describe longitudinal relationships, the objective of this study was to use longitudinal data to describe the temporal relationship and correlation between blood NEFA and BHBA concentrations during the periparturient period.

A convenience sample of 269 multiparous Holstein cows entering their second or greater lactation from 4 studies conducted at the Cornell University Teaching and Research Center Dairy was used in this study. All procedures involving animals were approved by the Cornell University Institutional Animal Care and Use Committee (Ithaca, NY) before the onset of experiments. All animals were clinically healthy before enrollment, and all diets fed to cows fell within normal composition ranges typically fed to transition dairy cows on commercial dairy farms in the United States. Longitudinal data for NEFA and BHBA concentrations from d 21 prepartum to 21 postpartum were recruited to address the present objective from 4 separate experiments [Smith et al. (2008), $\mathrm{n}=75$; Yasui et al. (2014), $\mathrm{n}=61$; McCarthy et al. (2015a,b), $\mathrm{n}=49$; Mann et al. (2015), $\mathrm{n}=84]$.

Plasma concentrations (Smith et al., 2008; Yasui et al., 2014; McCarthy et al., 2015b) and serum concentrations (Mann et al., 2015) of NEFA were analyzed by enzymatic analysis using a commercial kit [HR Series NEFA HR (2), Wako Pure Chemical Industries, Osaka, Japan]. Data for NEFA were reported as microequivalents per liter and converted into millimoles per liter by multiplying by a factor of 0.001 . Plasma concentrations of BHBA were analyzed by enzymatic analysis (BHBA dehydrogenase) using commercial products [nicotinamide adenine dinucleotide and Tris (hydroymethyl) aminomethane, Sigma-Aldrich; 3-hydroxybutyrate dehydrogenase, Roche Diagnostics Co., Indianapolis, IN] using the methods of Williamson et al. (1962) for all experiments except Mann et al. (2015), which measured whole-blood concentrations of BHBA cow-side using the Precision Xtra meter (Abbott Laboratories, Abbott Park, IL).

Statistical computations were performed using SAS software (version 9.3; SAS Institute Inc., Cary, NC). Data for NEFA and BHBA from d -21 to +21 relative to parturition were subjected to repeated-measures ANOVA using PROC MIXED of SAS and the RE-
PEATED statement for time. The degrees of freedom for PROC MIXED were estimated using the KenwardRoger option in the model statement. The fixed effect was time and the random effect was cow nested within study to account for between-study variation. A prepartum covariate (week before enrollment) was used for both NEFA and BHBA to account for differences in baseline values. The BHBA test method (enzymatic analysis vs. Precision Xtra meter) was included as a covariate in the initial model for BHBA; however, it was removed from the final model $(P=0.69)$. Four covariance structures were tested: compound symmetry, heterogeneous compound symmetry, first-order autoregressive, and heterogeneous first-order autoregressive. The compound symmetry covariance structure resulted in the smallest Akaike information criterion. Results were reported as least squares means and 95\% CI.

Postpartum hyperketonemia (HYK) was defined as a blood BHBA $\geq 1.2 \mathrm{mmol} / \mathrm{L}$ (McArt et al., 2012b); $\geq 0.70 \mathrm{mmol} / \mathrm{L}$ was used as a cut point for elevated postpartum concentrations of NEFA (Ospina et al., 2013). The daily incidence of HYK was computed for the time interval of 3 to 21 DIM according to McArt et al. (2012b). Animals were considered at risk if they had not previously had an episode of HYK.

To represent data over time, the area under the curve (AUC) for all cows in the data set were calculated using the midpoint rule as described by Cardoso et al. (2011). Prepartum AUC calculations included data observations from $\mathrm{d}-14$ to -1 , postpartum AUC calculations included data observations from d 0 to 21 , and total AUC calculations included data observations from d -14 to 21 relative to parturition. Observations from $\mathrm{d}-21$ to -15 were too infrequent to compute AUC because the target interval in sampling day in some cases could not be met due to variation in actual calving date. Data from cows with fewer than 4 observations of NEFA and BHBA for prepartum time points (59 cows) and fewer than 6 for postpartum time points (1 cow) were excluded from AUC calculations. Relationships between data for prepartum, postpartum, and total transition period NEFA and BHBA AUC were analyzed using the PROC CORR statement with the Pearson option in SAS. Day of maximum NEFA and BHBA concentration of each metabolite was determined for each individual cow in the data set before statistical analysis. Descriptive statistics were calculated using PROC MEANS, and Pearson correlations for individual maximum NEFA and corresponding BHBA and individual maximum BHBA and corresponding NEFA were calculated in SAS.

The objective of this study was to use longitudinal data to describe the temporal relationship and correlation between blood NEFA and BHBA concentrations 

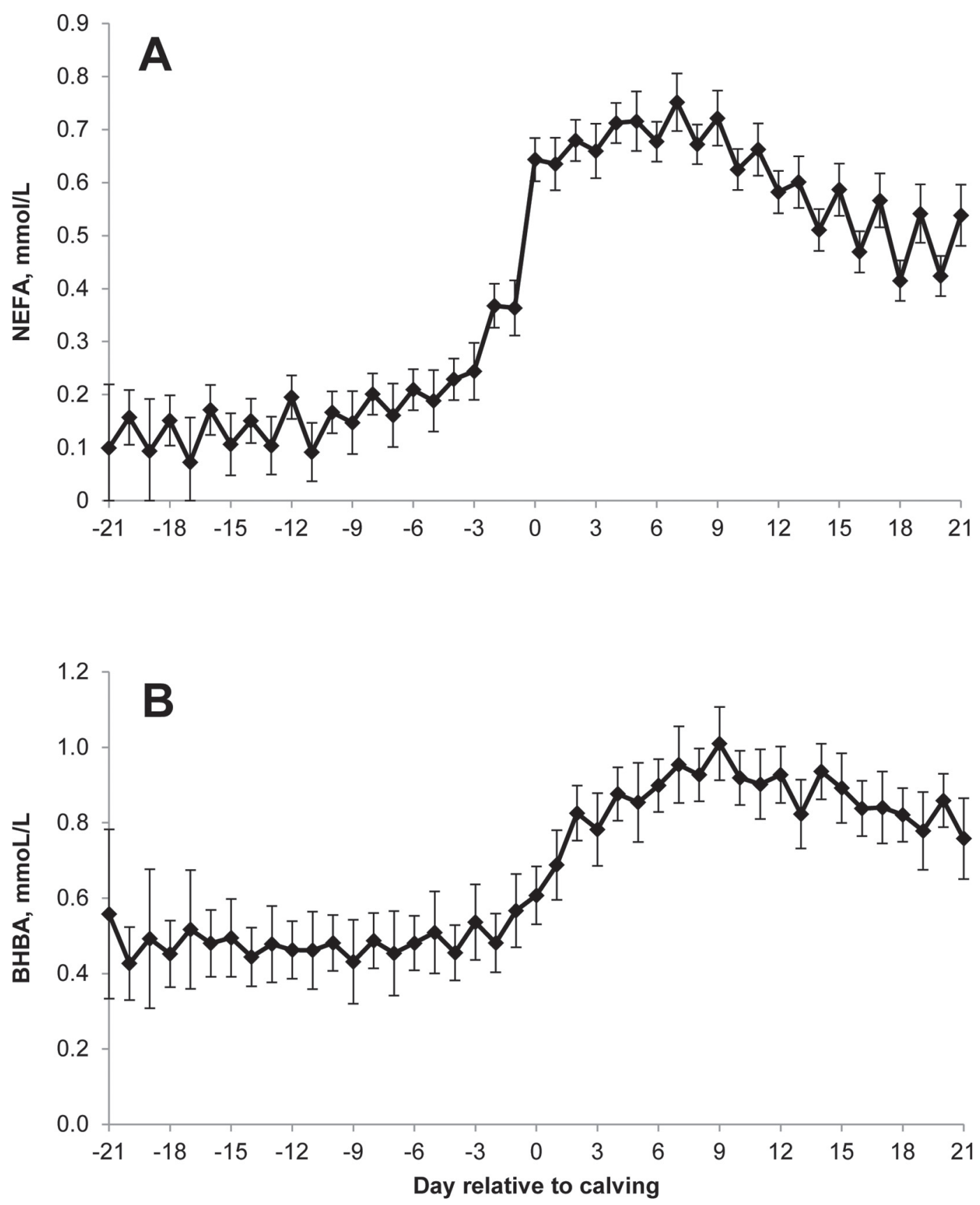

Figure 1. Least squares means for plasma $(\mathrm{n}=185)$ and blood $(\mathrm{n}=84)$ concentrations of $(\mathrm{A}) \mathrm{NEFA}(\mathrm{mmol} / \mathrm{L})$ and $(\mathrm{B})$ BHBA $(\mathrm{mmol} / \mathrm{L})$ in 269 multiparous Holstein cows from d 21 prepartum to d 21 postpartum; error bars represent 95\% CI.

during the periparturient period. Figure 1 depicts overall blood concentrations of NEFA (Figure 1A) and BHBA (Figure 1B) from d 21 prepartum to d 21 postpartum.

Of all 269 cows in the data set, 117 had at least one event of HYK $(43.5 \%)$, and 202 cows $(75.1 \%)$ had at least one event of elevated postpartum NEFA concentrations between 3 and 21 DIM. There were a total of 2,232 sampling events between 3 and 21 DIM, of which $393(17.61 \%)$ yielded a concentration $\geq 1.2$ $\mathrm{mmol} / \mathrm{L}$ for BHBA, and $679(30.42 \%)$ a concentration of NEFA $\geq 0.70 \mathrm{mmol} / \mathrm{L}$. When considering all postpartum sample days, there were 2,615 sampling events for BHBA and NEFA concentrations in the first $21 \mathrm{~d}$ postpartum; 415 events yielded a BHBA concentration $\geq 1.2 \mathrm{mmol} / \mathrm{L}(15.9 \%)$ and 817 events yielded a NEFA 
Table 1. Characteristics of the distribution of postpartum day of maximum NEFA (mmol/L) and maximum $\mathrm{BHBA}(\mathrm{mmol} / \mathrm{L})$ for individual cows

\begin{tabular}{lllccl}
\hline Item & Mean & Median & Minimum & Maximum & SD \\
\hline Maximum NEFA & & & & & \\
Day & 6.8 & 6 & 0 & 22 & 5.3 \\
Concentration, mmol/L $_{\text {BHBA }^{1}}$ & 1.08 & 1.03 & 0.28 & 2.17 & 0.40 \\
Maximum BHBA $_{\text {Day }}$ & 0.92 & 0.79 & 0.24 & 5.05 & 0.62 \\
Concentration, mmol/L $_{\text {NEFA }^{2}}$ & 9.6 & 8 & 0 & & \\
\hline
\end{tabular}

${ }^{1}$ BHBA concentration $(\mathrm{mmol} / \mathrm{L})$ on the day of maximum NEFA concentration.

${ }^{2}$ NEFA concentration $(\mathrm{mmol} / \mathrm{L})$ on the day of maximum BHBA concentration.

concentration $\geq 0.70 \mathrm{mmol} / \mathrm{L}(31.2 \%)$. We observed the highest HYK incidence at 4 DIM in the current study (data not shown), which is similar to the peak incidence at 5 DIM reported by McArt et al. (2012b). In the previous study, the authors observed that cows with a first HYK positive test between 3 to 9 DIM had higher risks for negative downstream health events and production consequences than cows with a first HYK positive test from 10 to 16 DIM. In the current study, we also had information on BHBA concentrations from cows sampled on 0,1 , and 2 DIM. Although cows sampled on d 0, 1, and 2 were used in the Chapinal et al. (2011) and Roberts et al. (2012) studies and included in the first week postpartum, the concentrations on those specific days were not reported separately. Currently, there is a lack of data on the interpretation of early HYK incidence before 3 DIM. However, because $5.9 \%$ of the cows sampled on $\mathrm{d} 0,2.2 \%$ of the cows sampled on $\mathrm{d} 1$, and $17.9 \%$ of the cows sampled on $\mathrm{d}$ 2 had BHBA concentrations $>1.0 \mathrm{mmol} / \mathrm{L}$ in the current data set, further investigation of the relationship of early postpartum elevated BHBA concentrations with downstream production outcomes is warranted.

Characteristics of the distribution of postpartum day of maximum NEFA (mmol/L) and maximum BHBA $(\mathrm{mmol} / \mathrm{L})$ for individual cows are presented in Table 1. The mean and median days of maximum NEFA concentration were 6.8 and $6 \mathrm{~d}$, respectively, with an occurrence range between 0 and $22 \mathrm{~d}$, whereas the mean and median days of maximum BHBA were 9.6 and 8 $\mathrm{d}$, respectively, with an occurrence interval between 0 and $22 \mathrm{~d}$. Although the largest proportion of cows had a maximum NEFA and BHBA on the same day (16.5\% of cows), the day of maximum BHBA occurred from 19 to $1 \mathrm{~d}$ before day of maximum NEFA ( $30.1 \%$ of cows) to 1 to $22 \mathrm{~d}$ after ( $53.4 \%$ of cows). In early lactation studies that have published results of NEFA and BHBA concentrations over time, the peak of mean NEFA concentration occurs before the peak of the mean BHBA (Hammon et al., 2009; Janovick et al., 2011). However, we observed a large degree of variation in the time of peak concentration for those metabolites in the periparturient period. To our knowledge, this is the first study reporting ranges in day of maximum NEFA and BHBA concentrations. Although the largest proportion of cows had maximum NEFA and BHBA concentrations on the same day, we found considerable betweencow variation. We observed similar variation in the day on which NEFA concentration was first $\geq 0.70 \mathrm{mmol}$ /L and day of first HYK event (data not shown), again indicating a large degree of individual cow variation between the occurrence of each of these events.

Areas under the curve for transition period NEFA and BHBA were calculated to represent cumulative effects of NEFA and BHBA concentrations over time. Pearson correlations between prepartum, postpartum, and total NEFA and BHBA AUC are presented in Table 2. Prepartum NEFA AUC was not correlated with prepartum BHBA AUC $(\mathrm{r}=-0.07)$. As depicted in Figure 2, we observed a large range in postpartum NEFA AUC, whereas postpartum BHBA AUC showed less variation, leading to a relatively small correlation coefficient of 0.26 . We detected a relationship between total NEFA AUC and total BHBA AUC $(P=0.001)$; however, the correlation coefficient indicated a weak relationship $(\mathrm{r}=0.20)$. Due to the lack of relationship between NEFA and BHBA AUC, along with the large variation in day to maximum NEFA and BHBA, Pearson correlations were calculated to determine if the relationship between individual cow NEFA and BHBA on their respective days of peak concentration improved the associations of these metabolites. Correlations were weak $(\mathrm{r} \leq 0.25$; data not shown) between NEFA concentrations on the day of maximum NEFA and the corresponding day's BHBA concentration as well as BHBA concentrations on the day of maximum BHBA and corresponding day's NEFA concentration.

Although we anticipated that AUC might help explain the relationship between the 2 metabolites better than single measurements, the correlations between 
Table 2. Pearson correlations between prepartum, postpartum, and total NEFA area under the curve (AUC) and prepartum, postpartum, and total BHBA AUC

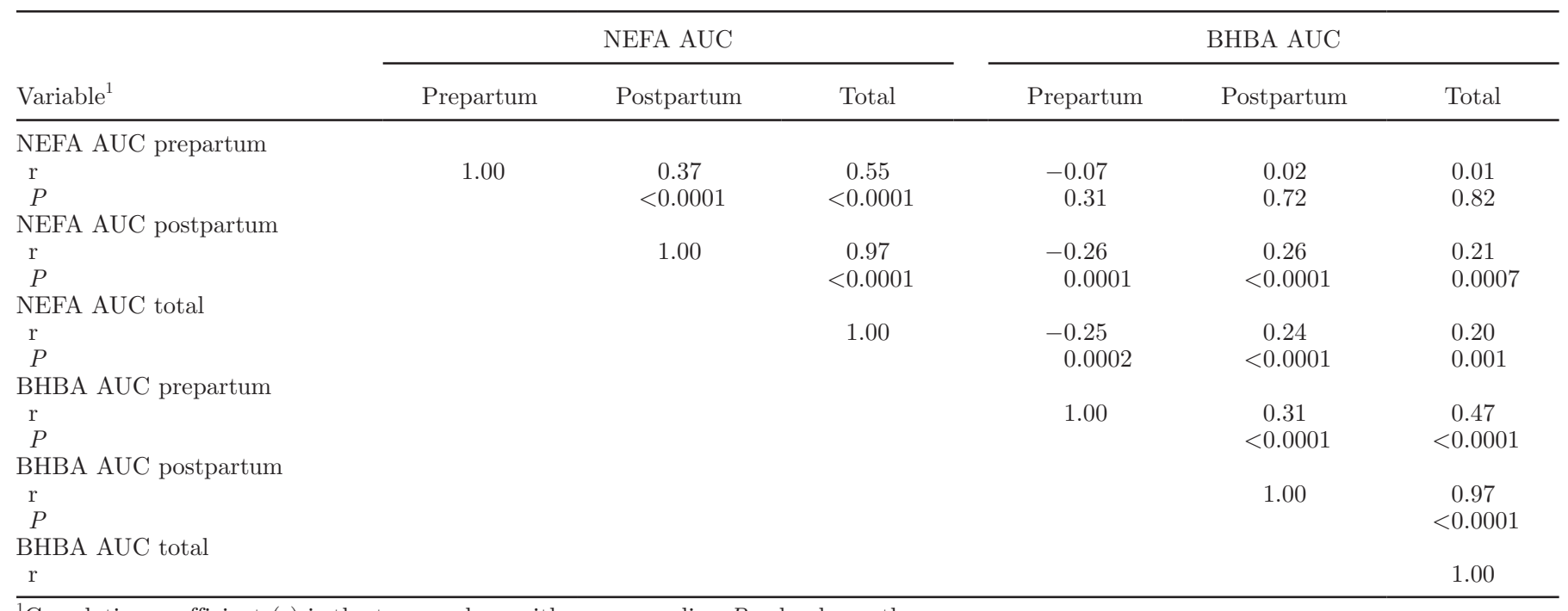

${ }^{1}$ Correlation coefficient (r) is the top number, with corresponding $P$-value beneath.

NEFA and BHBA AUC in the current study were weak. In light of this, we examined the relationship between NEFA and BHBA on the day of maximal concentration for individual cows as well as stratifying AUC data based on postpartum BCS $(\leq 3.25$ vs. $\geq 3.5)$, disease status, milk production $(<38 \mathrm{~kg} / \mathrm{d}$ vs. $\geq 38 \mathrm{~kg} / \mathrm{d})$, and postpartum DMI ( $<19 \mathrm{~kg} / \mathrm{d}$ vs. $\geq 19 \mathrm{~kg} / \mathrm{d})$; however, this did not improve relationships between NEFA and BHBA in a biologically meaningful way $(r<0.50$; data not shown).
The lack of relationship between NEFA and BHBA either on the day of maximum concentration or as AUC may be partially explained by the ketone body synthesis pathway. Because a large portion of the hepatic glucose output is directed toward lactose synthesis in the mammary gland, alternative substrates are needed for peripheral tissue energy metabolism, especially during the early postpartum period. Literature generally describes the main substrate for ketone body synthesis in the liver as being the oxidation of NEFA mobilized

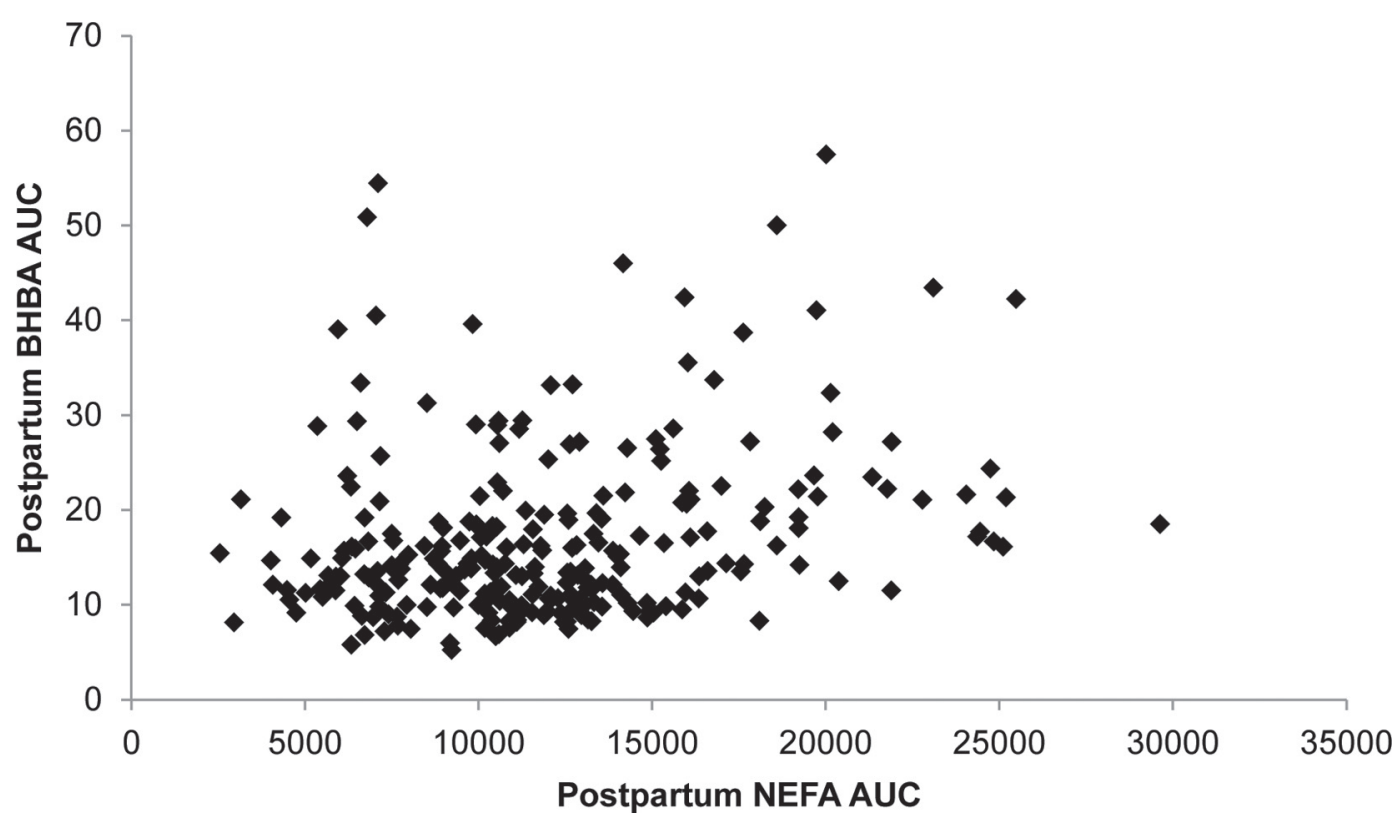

Figure 2. Associations of area under the curve (AUC) for postpartum NEFA and BHBA $(\mathrm{n}=268$ cows; $\mathrm{r}=0.26 ; P<0.0001)$. 
from adipose tissue (Drackley et al., 2001; Vernon, 2005). However, a splanchnic metabolism study of Reynolds et al. (2003) observed that the contribution of NEFA carbon to BHBA synthesis cannot account for all of the carbon used in ketone body synthesis in the liver. Therefore, ketone synthesis not only depends on energy balance and availability of intermediates in the Krebs cycle, but could also be related to individual differences in hepatic gluconeogenic capacity. When there is a large supply of propionate (the main gluconeogenic substrate), ketone body synthesis is reduced (Zammit, 1990; Drackley et al., 2001). In light of the weak correlations between blood concentrations of NEFA and BHBA observed in the current study, along with the data of Reynolds et al. (2003), sources of carbon other than NEFA (e.g., lactate and ketogenic amino acids, Drackley et al., 2001) contributing to BHBA synthesis would help to explain the weak relationships observed between blood concentrations of NEFA and BHBA.

In conclusion, we found a weak relationship between blood concentrations of NEFA and BHBA during the periparturient period. A positive correlation existed between postpartum NEFA AUC and postpartum BHBA AUC; however, the correlation coefficient was low. Large variation was found between the day of maximum NEFA concentration within the first 21 DIM and day of maximum BHBA concentration for the same period, and the range in days for both the mean and median day of maximum concentrations was very large. Overall, our data set showed a weak relationship between blood concentrations of NEFA and BHBA during the periparturient period of dairy cows, suggesting that caution should be exerted when trying to extrapolate relationships between NEFA and BHBA data.

\section{ACKNOWLEDGMENTS}

The authors sincerely appreciate and gratefully acknowledge the assistance of G. Birdsall and the staff at the Cornell University Dairy Teaching and Research Center (Ithaca, NY) for their care of the cows on the studies used in this analysis, as well as former Cornell graduate students T. Yasui and K. L. Smith for overseeing the collection of data on the other studies used in this analysis.

\section{REFERENCES}

Cardoso, F. C., W. Sears, S. J. LeBlanc, and J. K. Drackley. 2011. Technical note: Comparison of 3 methods for analyzing areas under the curve for glucose and nonesterified fatty acids concentrations following epinephrine challenge in dairy cows. J. Dairy Sci. 94:6111-6115.
Chapinal, N., M. E. Carson, T. F. Duffield, M. Capel, S. Godden, M. W. Overton, J. E. P. Santos, and S. J. LeBlanc. 2011. The association of serum metabolites with clinical disease during the transition period. J. Dairy Sci. 94:4897-4903.

Drackley, J. K., T. R. Overton, and G. N. Douglas. 2001. Adaptations of glucose and long-chain fatty acid metabolism in liver of dairy cows during the periparturient period. J. Dairy Sci. 84:E100E112.

Duffield, T. F., K. D. Lissemore, B. W. McBride, and K. E. Leslie. 2009. Impact of hyperketonemia in early lactation dairy cows on health and production. J. Dairy Sci. 92:571-580.

Garverick, H. A., M. N. Harris, R. Vogel-Bluel, J. D. Sampson, J. Bader, W. R. Lamberson, J. N. Spain, M. C. Lucy, and R. S. Youngquist. 2013. Concentrations of nonesterified fatty acids and glucose in blood of periparturient dairy cows are indicative of pregnancy success at first insemination. J. Dairy Sci. 96:181-188.

Hammon, H. M., G. Stürmer, F. Schneider, A. Tuchscherer, H. Blum, T. Engelhard, A. Genzel, R. Staufenbiel, and W. Kanitz. 2009. Performance and metabolic and endocrine changes with emphasis on glucose metabolism in high-yielding dairy cows with high and low fat content in liver after calving. J. Dairy Sci. 92:1554-1566.

Janovick, N. A., Y. R. Boisclair, and J. K. Drackley. 2011. Prepartum dietary energy intake affects metabolism and health during the periparturient period in primiparous and multiparous Holstein cows. J. Dairy Sci. 94:1385-1400.

LeBlanc, S. J., K. E. Leslie, and T. F. Duffield. 2005. Metabolic predictors of displaced abomasum in dairy cattle. J. Dairy Sci. $88: 159-170$.

Mann, S., F. A. Leal Yepes, T. R. Overton, J. J. Wakshlag, A. L. Lock, C. M. Ryan, and D. V. Nydam. 2015. Dry period plane of energy: Effects on feed intake, energy balance, milk production and composition in transition dairy cows. J. Dairy Sci. 98:3366-3382.

McArt, J. A. A., D. V. Nydam, and G. R. Oetzel. 2012a. A field trial on the effect of propylene glycol on displaced abomasum, removal from herd, and reproduction in fresh cows diagnosed with subclinical ketosis. J. Dairy Sci. 95:2505-2512.

McArt, J. A. A., D. V. Nydam, and G. R. Oetzel. 2012b. Epidemiology of subclinical ketosis in early lactation dairy cattle. J. Dairy Sci. 95:5056-5066.

McArt, J. A. A., D. V. Nydam, G. R. Oetzel, T. R. Overton, and P. A. Ospina. 2013. Elevated non-esterified fatty acids and $\beta$-hydroxybutyrate and their association with transition dairy cow performance. Vet. J. 198:560-570.

McCarthy, M. M., T. Yasui, C. M. Ryan, G. D. Mechor, and T. R. Overton. 2015a. Performance of early lactation dairy cows as affected by dietary starch and monensin supplementation. J. Dairy Sci. 98:3335-3350.

McCarthy, M. M., T. Yasui, C. M. Ryan, S. H. Pelton, G. D. Mechor, and T. R. Overton. 2015b. Metabolism of early lactation dairy cows as affected by dietary starch and monensin supplementation. J. Dairy Sci. 98:3351-3365.

Ospina, P. A., J. A. A. McArt, T. R. Overton, T. Stokol, and D. V. Nydam. 2013. Using nonesterified fatty acids and $\beta$-hydroxybutyrate concentrations during the transition period for herd-level monitoring of increased risk of disease and decreased reproductive and milking performance. Vet. Clin. North Am. Food Anim. Pract. 29:387-412.

Ospina, P. A., D. V. Nydam, T. Stokol, and T. R. Overton. 2010a. Evaluation of nonesterified fatty acids and beta-hydroxybutyrate in transition dairy cattle in the northeastern United States: Critical thresholds for prediction of clinical diseases. J. Dairy Sci. 93:546-554.

Ospina, P. A., D. V. Nydam, T. Stokol, and T. R. Overton. 2010b. Associations of elevated nonesterified fatty acids and beta-hydroxybutyrate concentrations with early lactation reproductive performance and milk production in transition dairy cattle in the northeastern United States. J. Dairy Sci. 93:1596-1603.

Ospina, P. A., D. V. Nydam, T. Stokol, and T. R. Overton. 2010c. Association between the proportion of sampled transition cows with increased nonesterified fatty acids and beta-hydroxybutyrate and 
disease incidence, pregnancy rate, and milk production at the herd level. J. Dairy Sci. 93:3595-3601.

Reynolds, C. K., P. C. Aikman, B. Lupoli, D. J. Humphries, and D. E. Beever. 2003. Splanchnic metabolism of dairy cows during the transition from late gestation through early lactation. J. Dairy Sci. 86:1201-1217.

Roberts, T., N. Chapinal, S. J. LeBlanc, D. F. Kelton, J. Dubuc, and T. F. Duffield. 2012. Metabolic parameters in transition cows as indicators for early-lactation culling risk. J. Dairy Sci. 95:30573063.

Smith, K. L., M. R. Waldron, L. C. Ruzzi, J. K. Drackley, M. T. Socha, and T. R. Overton. 2008. Metabolism of dairy cows as affected by prepartum dietary carbohydrate source and supplementation with chromium throughout the periparturient period. J. Dairy Sci. 91:2011-2020.
Vernon, R. G. 2005. Lipid metabolism during lactation: A review of adipose tissue-liver interactions and the development of fatty liver. J. Dairy Res. 72:460-469.

Williamson, D. H., J. Mellanby, and H. A. Krebs. 1962. Enzymic determination of $\mathrm{D}(-)-\beta$-hydroxybutyric acid and acetoacetic acid in blood. Biochem. J. 82:90-96.

Yasui, T., J. A. A. McArt, C. M. Ryan, R. O. Gilbert, D. V. Nydam, F. Valdez, K. E. Griswold, and T. R. Overton. 2014. Effects of chromium propionate supplementation during the periparturient period and early lactation on metabolism, performance, and cytological endometritis in dairy cows. J. Dairy Sci. 97:6400-6410.

Zammit, V. A. 1990. Ketogenesis in the liver of ruminants-Adaptations to a challenge. J. Agric. Sci. 115:155-162. 